Jadranka Kaluđerović

\title{
Montenegro: from equity towards efficiency
}

\begin{abstract}
Transition processes in the case of Montenegro were burdened by armed conflict in the surrounding countries, sanctions and inappropriate economic policies. All this contributed to a significant decrease in living standards, especially of population groups with low levels of education, skills and working performance. In addition, the inflow of Roma, refugees and internally displaced people increased the percentage of the population considered vulnerable. Recent positive economic trends have had positive implications for living standards and have made possible the mobilisation of resources that could be invested in the reforms of the labour market, education and social systems. Significant steps have been made. However, the implementation of active measures and decentralisation, as well as systems of control and monitoring, are still lacking. Social policy is not well targeted; labour market measures are not focused on the most vulnerable; and education reform is still not giving positive results in terms of quality and the fulfilment of the needs of the labour market.
\end{abstract}

Keywords: poverty, unemployment, social welfare reform, employment protection, active labour market policies, education reform, discrimination, adult and vocational education

Introduction

Montenegro is a small Balkan country (620 740 inhabitants according to the 2003 census) and was the least developed country in the former Socialist Federal Republic of Yugoslavia. During the nineties, economic activity in Montenegro was (due to the dissolution of the SFRY, war and sanctions) at a very low level. For the first three years of that decade, economic activity decreased by more than $50 \%$. This was followed by a few years of slight economic recovery, which was again disturbed by external factors, such as the NATO bombing, as well as the political disputes between Serbia and Montenegro (at that time Montenegro was part of the Federal Republic of Yugoslavia, a state created from Serbia and Montenegro after the dissolution of SFRY).

In 1997, the Montenegro government distanced itself from Serbia and commenced independent economic reforms. 2000 was the year in which, thanks to the overall transition efforts, the first glimpses of economic recovery in Montenegro were noticed. In 2006, Montenegro voted for independence in a referendum and became an independent state in the June. At the end of 2008, Montenegro applied for, and subsequently obtained, the status of EU candidate country.

The low level of economic activity during the nineties had consequences for the high rate of unemployment and the low living standards of the Montenegrin population. From 2000, economic activity recorded a positive growth path, while the structure of 
the economy changed towards services taking an increasing share of overall economic activity. Some sectors, such as construction and tourism, experienced significant growth and became engines for economic expansion. These positive trends improved the living standards of the population and also created new requirements and opportunities for human capital in Montenegro. On the other hand, thanks to increased economic activity, the budget experienced a surplus for the first time in recent history. Such additional resources could, then, be used for the improvement of the social and education systems, as well as for other policies.

\section{The case for a trade-off in social policy}

The first Poverty Assessment for Montenegro was produced in 2003 and was based on a household survey conducted by the independent economic think tank, the Institute for Strategic Studies and Prognoses (ISSP), with the support of the World Bank. In 2004 , the same survey, fully representative of the population as it included marginalised groups such as Roma, refugees and internally displaced people, showed that 12.2 per cent of the population lived in absolute material poverty (i.e. below the poverty line, which was calculated at a level of $€ 107$ per month). The newest comparable data that can be obtained from the ISSP/UNDP Social Exclusion Survey, conducted in April 2008 , shows that the poverty rate is at a level of 10.8 per cent. The data also shows that the percentage of the population living below the poverty line has declined during the period under observation, but poverty nevertheless remains stable, despite the recorded economic growth and wage increase. ${ }^{1}$

It may be concluded that poverty in Montenegro is low. However, poverty estimates are very sensitive to the poverty threshold. Almost one-third of the population ( 28 per cent) is classified as economically vulnerable, i.e. living below the vulnerability line which has been set at the level of $50 \%$ of the poverty line. The poverty gap is equal to 2.7 per cent, while the severity of poverty is 0.9 , according to the 2008 data.

One of the characteristics of Montenegro is the significant difference in the extent of poverty among the regions. Poverty is lowest in the south and central regions, whereas poverty rates $(19.2 \%)$, the poverty gap $(4.9 \%)$ and the severity of poverty (1.7) are all significantly higher in the north. More than one-half of the poor population (62 per cent) live in the north. This situation is not surprising as the northern part of Montenegro is the least economically-developed region: tourism and construction activities, the two fastest-growing sectors, are concentrated in other regions. In contrast, the segment of the population considered poor is 26.5 per cent in the central part of the country and 11.1 per cent in the southern regions.

The poverty profile shows that size of household, activity status and the level of education of the head of the household are the main determinants of living standards. Less than four per cent of people living in households with three or fewer members are poor, while this percentage among households with four or more members is $13.7 \%$. Slightly more than 20 per cent of households whose head is not employed but not retired are poor, while 10.7 per cent of households whose head is retired and not employed are in the same position. However, poverty exists in many households where the head is

\section{ISSP/UNDP National Human Development Report for 2008.}


employed; such households represent slightly more than one-third of poor households. Out of the total number of households whose heads have only primary education, 15.3 per cent are poor.

Data for 2008 shows that poverty rates vary among different vulnerable groups. The highest poverty rate is among the $\mathrm{RAE}^{2}$ population $(36 \%)$, displaced people (34\%), and beneficiaries of the social welfare system (30\%). Poverty is not so significantly high for pensioners $(15.7 \%)$, the long-term unemployed $(12.9 \%)$ and people with disabilities $(11.9 \%)$.

In order better to target its activities in combating poverty, the Montenegrin government adopted in 2003 its Poverty Reduction Strategy. However, this very ambitious set of activities and projects was only partially implemented.

Reform of the social protection system in Montenegro started with the reform of the pension system (2003) and continued with the reform of social and child protection (2004). In 2007, the government adopted the Strategy for Social and Child Welfare Development (2008-2012). The reform of the social protection system is focused on reforming financial benefits and enhancing the system's accountability by providing a social welfare system.

Social protection spending in Montenegro made up around $11 \%$ of GDP in 2008 and $16 \%$ in 2009 . In comparison with EU member states, Montenegro falls into the category of countries with medium-level social protection expenditures. Social welfare benefit spending was at a level of $1 \%$ of GDP in 2008 and $1.3 \%$ of GDP in 2009. Onethird of social welfare benefits goes on family allowance, whose purpose is to provide a minimum income.

The social protection system is very centralised, while social services are provided by state institutions. The main institution responsible for social protection is the Ministry of Labour and Social Welfare. Aside of the Ministry, there are a number of institutions (such as the ten Centres for Social Work and other residential institutions) which are charged with social protection at the local level. Services provided at the local level are very under-developed due to the high degree of financial and managerial centralisation which discourages local authorities from initiating new services. Moreover, staff at this level are generally educated but need additional training in order to fulfil the very complex requirements of service users. Data from the 2008 ISSP/UNDP survey shows that, in general, social welfare beneficiaries are dissatisfied with social welfare services (3.6 on a scale from 1 to 10 ). An additional problem is the under-developed co-operation and communication between the social system and other systems in the country such as health, education, etc.

Analysis conducted by ISSP in 2006 showed that the allocation of social welfare benefits among the poor is very low, as only $13.3 \%$ of families from the poorest quintile receive them, whereas $54.2 \%$ of total family allowances benefits go to families in the poorest quintile. The share of the family allowance in total consumption is $10.5 \%$ for poor households, which is due to social programmes being poorly targeted and inadequate. If we consider these, as well as the information that $30 \%$ of the recipients of 
household benefits are poor, we may conclude that the targeting of social welfare benefits is very low.

According to data presented in the Strategy for Social and Child Welfare Development, the amounts of monthly family material support range from $€ 55$ (for a single family) to $€ 104.50$ (for families with five or more members). Child allowance amounts range from $€ 16.50$ to $€ 27.50$. Prior analysis carried out by ISSP shows that, if we assume that the only income that families have is social assistance benefits, then family material support and child allowance, where applicable, compensate below $50 \%$ of the poverty line. This leads to the conclusion that social benefits are not sufficient and only reduce the vulnerability of households; this means that they are better off, but remain poor.

In addition, the timing of social assistance benefits is poor and all allowances are paid to beneficiaries with significant delay. The delay depends on the type of benefit: family material support and child allowance are paid with delays of six months, while other people on care benefits may have to wait twelve months for the first payment.

This analysis has shown that there is significant room for the improvement of the effectiveness of social protection in Montenegro, primarily in terms of the targeting of social protection and the adequacy of social benefits as well as in the improvement of transparency and the accessibility of data and information. This would require a new design of the social protection system, a revision of the eligibility criteria and a simplification of administrative procedures, in addition to an improvement in the authorisation of service issuance and delivery. Decentralisation of management and funding, together with the improvement of the human capacities of service providers, should enable an increase in the quality of existing services and the development of new ones, in addition to their effective use by different client groups.

Also, the development of residential care would significantly contribute to the increased efficiency, as well as the equity, of the social protection system.

\section{The case for a trade-off in employment policy}

The transition process and the political changes that have occurred in the western Balkan region over the last twenty years have had a significant impact on the performance of the Montenegrin labour market. At the beginning of the transition process in the early nineties, unemployment in Montenegro already stood at a relatively high level, with one-fifth of the active population being unemployed. At the same time, employment was at a relatively low level, with roughly one-half of the working age population being active. In the period following 1991, unemployment increased, following major setbacks in economic activity. However, the decrease in unemployment was not as sharp as the decline in economic activity due to the high level of employment protection. Also, employment in the informal sector, tolerated by the authorities, has compensated for job losses in the public sector companies which have been the dominant employers. The growing private sector has generated new jobs; however, the pace of job creation in the private sector has not been as fast as that of job destruction in the public sector.

Registered unemployment recorded its highest level in 2000, reaching 83500 individuals, while, at the same time, registered employment accounted for 140000 individuals. On the other hand, due to the high incidence of undeclared work, the employment situation was not as drastic as presented by the official figures. The labour 
market, however, was still characterised by some serious imbalances - of which some continue to be present - such as the high incidence of long-term unemployment; the imbalance between labour supply and demand; the lack of quality jobs in terms of good working conditions and wages; the low level of compliance with employees' rights; etc.

The value of the overall employment protection index for Montenegro up to 2008 was 4.1, making the Montenegrin labour market among the most rigid in Europe. The index for permanent employment was 3.2. Permanent contracts could not be cancelled without following the legal procedure: one month's notice (written); and provision or else rights (employment in the same or another company in a different post which matches the level of education, retraining or pre-qualification, or six months' salary as a severance payment). The law did not differentiate either in notice periods or severance payments on the basis of the working experience of employees.

The regulations on temporary contracts in Montenegro were even stricter than for permanent contracts. The law allowed for a nine-month regular contract which could not be renewed. If, according to the law and in the opinion of the labour inspectorate, the need for a particular worker existed after the nine-month period, then this contract had to be treated as a permanent labour contract. The law allows temporary contracts only for objective reasons (a temporary increase in workload; the replacement of an absent worker; project work; etc).

The control of collective dismissals was the strictest part of labour regulation in Montenegro. The index of the rigidity of collective dismissals in Montenegro was 5. Collective dismissal is defined as the dismissal of five or more workers, regardless of the size of the company. Workers, unions and the Employment Office of Montenegro must be informed of planned dismissals three months in advance. Furthermore, the employer must draft a programme of employees' rights - employment with the same or a different employer in different working positions, retraining and severance payments. The employer was obliged to offer the worker some of these rights, while the worker can choose which ones to use.

Despite the high rigidity of regulation, the level of compliance with the law is low, especially in the private sector. This is evidenced through the high share of the labour market which is taken by the informal economy, which ranged from $30 \%$ in 2001 to $22.6 \%$ in 2007 . According to the 2007 LFS survey results, $22.6 \%$ of employees work in unregistered companies or are unregistered workers in formal sector companies. In addition, $17.5 \%$ of registered employees have a partly registered wage: employers register a minimum wage, which is set by the General Collective Agreement, and pay social security contributions and taxes on this amount, while employees actually receive a higher amount.

In 2008, the parliament of Montenegro adopted a new Labour Code, which brings significant improvements in the regulation of the Montenegrin labour market. This law represents a significant improvement on the old one. The new law decreases the degree of employment protection and thus increases labour market flexibility. However, collective dismissals in Montenegro are still the most regulated when compared with neighbouring and European countries. In other areas, the Montenegrin labour market is among the most flexible in Europe, as indicated both by the value of the EPL (Em- 
ployment Protection by Legislation) index and the WB Doing Business Employing Workers index.

In the period from 2006 to 2008, along with the strong growth of the Montenegrin economy, the situation on the labour market improved, with substantial growth in employment and a sizable decrease in unemployment. The number of announced vacancies exceeded the number of the registered unemployed; thus, the mismatch between labour supply and labour demand became more evident. On the other hand, a huge number of people, over 50000 non-resident workers, were engaged in mainly seasonal jobs in construction, tourism and agriculture. There are many reasons for such a situation, among which predominate a lack of skills in the domestic workforce; the propensity of employers to hire non-residents, whose services/labour are cheaper; and the poor quality of the posts offered (low salaries, a lack of basic occupational health and safety regulations, non-compliance with the regulations in terms of leave and vacation days, etc).

The data on registered unemployment indicate that the percentage of male unemployed is higher than that of female unemployed, mainly due to the lower activity of the female population and job destruction being highest in the industry sector, which employed predominantly a male labour force. At the same time, job creation in Montenegro over the past several years has been mainly in the services sector, such as trade and tourism, which predominately engages a female labour force. The high incidence of long-term unemployment, with over $60 \%$ of unemployed people waiting for a job for over one year, is also an important issue, especially bearing in mind that those longterm unemployed mainly consist of redundant labour from industrial companies.

The Employment Agency of Montenegro (EAM) has implemented many active labour market policies (ALMPs), among which predominate loans for self-employment; apprenticeship programmes; training and retraining for the labour market, or a known employer; and public works. However, it is very difficult to assess the success of these programmes given that proper monitoring mechanisms are still lacking. According to the EAM, the most successful active labour market policy in Montenegro is the apprenticeship programme, since approximately $60 \%$ of beneficiaries stay on the job; the second most successful programme is training provided at the request of an employer.

Despite the success of some ALMPs, a focus on hard-to-employ individuals is still lacking or, to be more precise, is not delivering any results. A needs-based approach to policy formation and the development of partnerships among key stakeholder employers, education institutions and public employment services is still missing. The high numbers of vacancies which can be filled by the domestic workforce indicate that ALMPs and the education system in Montenegro have not fulfilled their primary aim and that scarce resources have not been used efficiently. A more co-ordinated approach to improving labour supply and demand in Montenegro, through ALMPs and education, could and should play an important role in the future development of the market in the way of making efficiency gains. At the same time, by improving the functioning of the whole system, especially in education, and focusing more on future demand and not on wasting resources by providing qualifications for which there is no demand, the public employment service could make a significant impact by focusing on disadvan- 
taged individuals, providing them with opportunities to participate fully in the labour market.

\section{The case for a trade-off in education}

Montenegro started its education reform in 2001 with the adoption of a blueprint document entitled Book for Change. The main principles on which this reform was based are: the decentralisation of the education system; equal education rights for all, regardless of gender, socio-cultural origin, ethnicity, physical or philological characteristics; and choice in accordance with abilities. The new education system is designed to respond to the individual needs of each child, as well as to the needs of specific target groups.

According to the existing legislation, all children have equal access to education, while primary education is compulsory and free for all. Equal access to secondary and higher education is founded on competition for enrolment based in turn on competitiveness.

The net attendance ratio for primary schools is $98 \%$, while the figure for secondary schools is $84 \%$. This is in line with the UNICEF Multiple Indicator Cluster Survey analysis (for primary schools, it is above the average and, for secondary schools, it is on the average for the region) and may be considered to be satisfactory. In contrast, the pre-primary enrolment ratio is $29 \%$, which is significantly lower than in the rest of the region. Meanwhile, the percentage of early school leavers among the young population is $9.2 \%$ for females and $15.5 \%$ for males which is actually better than among the EU-15.

The major change introduced by the reform of education is the extension of primary education from eight to nine years, which is expected to affect the overall education system. The figures show that compulsory schooling requirements are delivering positive results.

Despite the legislation for equal access, some population groups face difficulties in enrolling in the educational system. Among those groups are the RAE population, people with disabilities, children from poor families, the long-term unemployed, etc.

According to the existing data, only $7 \%$ of the Roma school-age population has been enrolled in the school system - $85 \%$ of them in primary school, $8 \%$ in secondary school and $7 \%$ in tertiary education. One of the main reasons for this is the bad economic situation (only $10 \%$ of this population has some kind of employment), given that parents cannot afford basic items such as clothes and footwear for their children. In addition, the educational level of the parents themselves is low and they do not understand the importance of education, so the RAE population needs significant support within the education process. Moreover, the lack of teaching staff able to teach the RAE language is a significant barrier to the enrolment of REA children in schools.

The government of Montenegro has adopted a Strategy for the Improvement of the Position of the RAE Population 2008/2012, which prescribes a set of actions to be implemented in order to support this population group, such as:

- creating the necessary conditions for the inclusion of REA children in pre-school

- developing a specific enrolment policy for RAE children 
- transferring RAE children who have been wrongly enrolled in special schools into regular schools

- fostering a motivation for education

- providing an adequate human resource base for work with the RAE population

- upgrading public awareness on the need to include the RAE population in regular education

- free scholarships at all education levels

- education of parents.

There are no exact data on the number of children with special needs in Montenegro. According to estimates prepared by the Ministry of Health, Labour and Social Welfare, their number is in the range of 6000 to 7000 . According to data from the Ministry of Education and Science, there are 3416 children with special needs who are enrolled in the education system. The Montenegrin government adopted in 2008 the Law on the Education of Children with Special Needs, as well as the Strategy for Inclusive Education. Some of the measures proposed by these documents have already been implemented, such as the training of teachers at all school levels, the establishment of mobile teams in support of inclusion and improvements in facilities, including entrances for pupils with disabilities. However, there is a need to improve conditions further for children with special needs.

The ISSP/UNDP survey showed that one of the biggest barriers for the long-term unemployed population is the lack of education and training necessary to compete on the labour market. This survey, as well as other sources, shows that the majority of the long-term unemployed has secondary education (more than $80 \%$ ). However, only small numbers of these people (less than $10 \%$ ) are attending some type of training. Others are not motivated or do not have the money to invest in the improvement of their education.

Adult education is a measure for the solution to unemployment, especially in the long-term. In pursuit of the Strategy for Adult Education, three centres for education and training have been established, while the new programme for primary school education for adults is one improvement in this area.

In addition, the government has adopted its Vocational Education Development Strategy 2010-2014. This is aimed at the development of the vocational education system in such a way that it will provide individuals with the possibility of obtaining the skills necessary for equal participation in the labour market, as well as for an advancement in their careers, personal development and further education. However, some concrete steps in the implementation of this strategy are still not that evident.

The financing of the education system was at a level of around $4 \%$ of GDP in 2008. However, financing is still fully centralised. Decentralisation was set as one of the main goals in all the strategic documents which have been adopted but implementation, in terms of the first-line transfer of financing to local governments, has not yet been carried out.

The Ministry of Education is preparing its budget plan in accordance with the principles of programme budgeting; however, a very high proportion of spending on education is still on wages. In OECD countries, the share of non-staff costs in total recurrent expenditure is $25.6 \%$, while this share in Montenegro is below $19 \%$. Thus, one of the 
major challenges is to increase spending on non-salary expenditures and to improve the quality of education more generally, while reducing staffing costs in the context of rising average salaries and the falling numbers of pupils in primary and secondary education.

On the other hand, learning outcomes are not satisfactory. According to the results of the PISA assessment conducted in 2006 (in mathematics, language and science), Montenegro was ranked $48^{\text {th }}$ out of 57 countries.

Data shows that $91.1 \%$ of students complete primary school while $98 \%$ of these students enrol in secondary school. Also, $70.8 \%$ of students enrolled in secondary schools are enrolled in vocational schools.

Thus, we may conclude that significant efforts have been made to increase access to education, although it is evident that the system is still inefficient as learning outcomes are very low and labour market needs are not being fulfilled. In addition, globalisation brings new challenges for human capital.

In order to respond to these challenges, the efficiency of the education system has to be improved in order to increase the quality of education at all levels. In these terms, possibilities such as the financing of pupils in higher education abroad, instead of opening new faculties in the country, or financing pupils to study in private faculties, should be considered as options. Additionally, the education of teachers and the improvement of the curricula, especially in vocational schools, have to be among the priorities.

In general, the settled goals and adopted strategies present a good basis for development but, in order to prevent them from being no more than dead documents, concrete actions are needed as regards their immediate implementation. An education and monitoring system has also to be developed. Actions must, furthermore, be focused on the further enrolment of children in pre-primary education institutions and on the increase of enrolment, attendance rates and quality of education at all levels. Special attention should be paid to Roma, children with special needs and children from poor families.

\section{Conclusions}

Transition from one economic system to another is difficult and challenging, primarily because it sets new standards and requirements for the whole population in terms of knowledge, skills and working performance. How someone uses these opportunities depends on personal capabilities but also on the ability to establish the best possible relationship between equity and efficiency in the provision of state services. However, we also have to bear in mind that a main precondition for that is having an environment which is conducive to wealth creation in the most efficient way.

In the case of the Montenegro labour market, social and education policy have been more focused on the fulfilment of the equity criteria than on the efficient allocation of resources. In that respect, further improvement has to be made in order to increase the efficiency of government programmes in these areas. The starting point has to be the education system, since good education is a precondition for a better position on the labour market and since, at the same time, it decreases the need for support from the social welfare system. Dedicating more resources to the education system (primarily, 
high quality education and training programmes) will have positive effects on the overall economic and social system in the country. Also, a decentralisation of financing should be implemented in order to mobilise funds from different sources and to engage more stakeholders to take active roles in the reform process.

Thus, in the education system, resources have to be employed in order to provide higher quality education and training to those who are interested, but also to give incentives to those groups who have limited access, caused mainly by their poor economic situation. In the area of social policy, a new system should be designed in order better to target the most vulnerable parts of the population (Roma, the poor, disabled, the long-term unemployed) and to provide them with sufficient resources for living. In the area of the labour market, measures should be targeted towards those who are in the most difficult position, as an increase in their employment possibilities decreases the costs of the welfare services provided to such groups in the long-run.

\section{References}

European Commission (2006a) Employment in Europe 2007 Brussels.

European Commission (2006b) Social Inclusion in Europe 2006 Brussels.

European Commission (2007) Montenegro 2007 Progress Report November.

European Commission (2008) Social Protection and Social Inclusion in Montenegro.

DGECFIN, WIIW and ISSP (2008) Study on adjustment capacity to shocks of EU candidate and potential candidate countries of the western Balkans, with a focus on labour markets Volume II Brussels.

ISSP Montenegro Economic Trends Issues 15-25, Podgorica.

ISSP Household Budget Survey Issues 1-13 2002-2004, Podgorica.

ISSP (2003) Living Standards and Poverty in Montenegro ISSP.

ISSP (2006) Public Social Assistance and the Poor-Coverage and Effectiveness ISSP Policy Paper.

ISSP/EAM (2007) Labour Force Survey 2007 ISSP and Employment Agency of Montenegro.

ISSP/Ministry of Labour and Social Affairs (2005) National Strategy for Resolving Issues of Refugees and Internally Displaced Persons, ISSP.

ISSP/UNDP (2003) Household Survey of RAE, refugees and IDPs ISSP.

ISSP/UNDP (2008) Human Development Report for Montenegro - Montenegro: Society for all UNDP.

Kaluđerović, J, A. Krsmanović and I. Vojinović (2006) Proportional tax-accelerator of economic development in Montenegro within EU project managed by European Agency for Reconstruction, ISSP Policy Paper.

Krsmanović, A and M. Walewski (2006) Labour market institutions in Montenegro A barrier to employment? ISSP Montenegro/CASE Poland. 
Ministry of Education and Science (2008a) Law on Education of Children with Special Needs.

Ministry of Education and Science (2008b) Strategy for Inclusive Education.

Ministry of Education and Science (2009) Vocational Education Development Strategy 2010-2014.

Ministry of Health, Labour and Social Welfare (2007) Strategy for Social and Child Protection 2008-2012.

MONSTAT (2004-2006) Labour Force Survey 2004, 2005 and 2006 MONSTAT: Podgorica.

MONSTAT (2000-2007) Statistical Year Book 2000, 2004, 2005 and 2006, MONSTAT: Podgorica. 